\title{
Chemoprotective effect of ascorbic acid on cyclophosphomide induced oral toxicity
}

\begin{tabular}{|c|c|}
\hline \multicolumn{2}{|c|}{ Ali Sultan Al-Refai * } \\
\hline \multicolumn{2}{|c|}{ Abstract } \\
\hline \multicolumn{2}{|c|}{$\begin{array}{l}\text { Background and objective: Oral mucositis is currently considered to be the most severe } \\
\text { complication of anticancer therapy such as cyclophosphamide (CTX). Ascorbic acid is a } \\
\text { well-known antioxidant, which can protect the body from damage caused by free radicals } \\
\text { that can be generated during normal metabolism as well as through exposure to toxins } \\
\text { and carcinogens. This study aimed to evaluate the effectiveness of ascorbic acid as } \\
\text { a treatment for CTX induced oral mucositis. } \\
\text { Methods: Forty Wister-albino rats, age about } 6-8 \text { weeks and weighing } 150-200 \mathrm{~g} \\
\text { were used. The rats were randomly divided by simple random allocation into two groups } \\
\text { ( } 20 \text { animals each). The control group was intraperitoneally injected with physiological } \\
\text { saline and the animals were grouped randomly into two groups: Saline/Water treated group } \\
\text { which were daily received intraperitoneal injection of distilled water, while the Saline/ } \\
\text { Ascorbic acid treated group received a daily intraperitoneal injection of ascorbic acid } \\
\text { (12mg/kg/day). For the induction of mucositis, a single dose (300 mg/kg) of CTX was } \\
\text { administered intraperitoneally to each animal in the study group, and the animals were } \\
\text { grouped randomly into two groups: CTX } / \text { Water treated group which was daily received } \\
\text { intraperitoneal injection of distilled water, while the CTX /Ascorbic acid treated group were } \\
\text { daily received intraperitoneal injection of } 12 \text { mg/kg /day of ascorbic acid. The animals } \\
\text { were sacrificed at day four and eight (five animals each) and the tongue was dissected } \\
\text { from the jaw for histological and immunohistochemical analysis. } \\
\text { Results: Ascorbic acid decreased the severity of the induced CTX oral mucositis by } \\
\text { a significant increase in epithelial thickness, significant decrease in damage score, and } \\
\text { significant increase in PCNA immune expression at day four and eight respectively } \\
\text { (P <0.05). } \\
\text { Conclusion: CTX chemotherapy has a deleterious effect on the oral mucosa leading } \\
\text { to marked morphometric and microscopic changes. Ascorbic acid can protect the oral } \\
\text { mucosa from CTX-induced cytotoxicity, and attenuate or decrease the associated injury. } \\
\text { Keywords: Ascorbic acid; Cyclophosphamide; Oral mucositis; Antioxidant; PCNA. }\end{array}$} \\
\hline Introduction & \\
\hline $\begin{array}{l}\text { Oral mucositis is currently considered to be } \\
\text { the most severe complication of anticancer } \\
\text { therapy, affecting } 40-80 \% \text { of patients } \\
\text { undergoing chemo-therapy and almost all } \\
\text { those undergoing radiotherapy of the head } \\
\text { and neck. }{ }^{1-2} \text { It may result in dose reduction } \\
\text { or discontinuation of chemotherapy or } \\
\text { unplanned treatment interruption. }{ }^{3} \text { It is } \\
\text { characterized by erythematous, erosive, } \\
\text { and ulcerative lesions in the oral cavity, } \\
\text { causing difficulty in eating and drinking. }\end{array}$ & $\begin{array}{l}\text { significant economic impact because } \\
\text { of increased hospitalization, and the } \\
\text { requirement of parenteral nutrition. }{ }^{5} \\
\text { Cyclophosphamide (CTX) is a nitrogen } \\
\text { mustard compound which is directly } \\
\text { targeting on the nucleic acid contents that } \\
\text { is the deoxyribonucleic acid (DNA) and } \\
\text { ribonucleic acid (RNA) and interferes with } \\
\text { DNA replication and RNA transcription. }{ }^{6-7} \\
\text { CTX, administered either alone or in } \\
\text { conjunction with other drugs, has proved }\end{array}$ \\
\hline
\end{tabular}


an effective treatment for different types of tumor, like disseminated Hodgkin's disease and non-Hodgkin lymphomas, acute leukemia, cancer of the breast and ovaries, myeloma, etc, and immune disorders like lupus and multiple sclerosis, and organ transplants. ${ }^{8-10}$ Oral mucositis is a common, debilitating complication of CTX therapy; furthermore, patients with damaged oral mucosa and reduced immunity are prone to opportunistic infections. ${ }^{11}$ The most common types of treatment for oral mucositis are topical antimicrobial agents, non-alcoholic mouth washes, supplementary amino acids, cryotherapy, low-level laser treatment, herbs and vitamins. ${ }^{12,13}$ Ascorbic acid is a well-known antioxidant, which can protect the body from damage caused by free radicals that can be generated during normal metabolism as well as through exposure to toxins and carcinogens. Ascorbic acid might ameliorate the oxidative damage by altering the antioxidant defense system. ${ }^{14}$ Unfortunately, at the present time, there is no widely accepted effective treatment for oral mucositis. The discovery of an intervention which could either prevent or reduce the severity of oral mucositis would have a hugely beneficial impact, not only clinically and economically, but also most important for the patient's quality of life. There is conflicting information on whether ascorbic acid was beneficial for the prevention of oral mucositis, and there is a need for a well-designed, conducted and reported trial. For this reason, this study aimed to evaluate the effectiveness of daily intraperitoneal injection of ascorbic acid as a treatment for the induced CTX oral mucositis. As variables to evaluate the grade of protection, we used histological and immunohistochemical investigations to clarify its effect on cellular proliferation.

\section{Methods}

Forty Wister-albino rats, aged 6-8 weeks and weighing 150-200 $\mathrm{g}$ were used in the study and cared in the animal house at the College of Medicine, Hawler Medical
University, Erbil, Kurdistan Region of Iraq, under standard laboratory conditions. Rats were maintained on a 12 hour light/dark cycle at $2^{\circ} 5 \pm 0 \mathrm{C}$. The animals were kept in standard room conditions and fed with a standard rat chow and allowed to drink water ad libitum. The research project was approved by the Research Ethics Committee at College of Dentistry, Hawler Medical University under the protocol.

Experimental design: Rats were randomly divided into two groups, the control group and the study group (20 animals each). In the control group, the animals were intraperitoneally injected with physiological saline $(0.9 \% \mathrm{NaCl})$ in the same manner and dose like CTX. The treatment for this group started one day before intra peritoneal injection of physiological saline, and the animals were grouped randomly into two groups (10 animals each): Saline/Water treated group which received daily intraperitoneal injection of distilled water, while the Saline/ Ascorbic acid treated group received daily intraperitoneal injection of ascorbic acid (12mg/kg/day; Redox- C 500 mg/5ml ampoule, Istanbul) diluted in distilled water. ${ }^{15}$ For the induction of mucositis in the study group, one high single toxic dose of CTX (300 mg/kg, Cytoxan Vial $1 \mathrm{mg}$, Halle/ Westfalen Germany) was administered intraperitoneally to each animal. ${ }^{16}$ The treatment started one day before intra peritoneal injection of CTX, and the animals were grouped randomly into two groups (10 animals each): CTX /Water treated group, they received daily intraperitoneal injection of distilled water, while the CTX /Ascorbic acid treated group received daily intraperitoneal injection of $12 \mathrm{mg} / \mathrm{kg} / \mathrm{day}$ of ascorbic acid diluted in distilled water. The animals were sacrificed by overdose of anesthesia (60 mg/kg ketamine) at day four and eight (five animals for each group), and the tongue was dissected from the jaw and a cross section of the middle third of the tongue of each animal was taken. 
Histological and immunohistochemical analysis: Specimens were fixed in $10 \%$ neutral buffered formalin for 24 hours, processed by standard paraffinembedding methods, sections were cut at $4 \mu \mathrm{m}$, deparaffinized, and stained with hematoxylin and eosin. The lightmicroscopic morphometric analysis to measure the epithelial thickness were assessed by two independent physicians, the thicknesses of all three layers of the epithelium which include stratum basale, stratum spinosum, and stratum granulosum was measured (the major epithelial thickness) in five photograph fields from each tongue mucosal epithelium section by objective micrometer at high power magnification (x400). Analysis for tongue damage scores was carried out among the groups. The damaged areas were evaluated for the following:

${ }^{*}$ Cell changes in stratified squamous epithelium such as hyperchromasia, pleomorphism, binucleation, and necrosis.

* Degeneration and vacuolar alteration of the basal layer.

* Congestion of blood vessels.

* Inflammatory infiltrate in the submucosa.

Five regions in the epithelial area and the connective tissue were selected (linearly adjacent to each other) and preceded with scoring the damage of these separate location. The changes were assessed by one blind evaluator to the type of the sample with scores of 0 to 5 . The semiquantitative scores reflect the animals examined as follows; Grade $0=$ Normal, Grade $1($ minimal $)=<5 \%$, Grade $2($ mild $)=$ $6-20 \%$, Grade 3 (moderate) $=21-50 \%$, Grade 4 (marked) $=51-75 \%$, and Grade 5 (severe) $=76-100 \%$. This method was modified from the method proposed by Üçuncu et al. $(2006)^{17}$ in orders to assess the degree of tongue mucositis. Cell proliferation was assessed by proliferating cell nuclear antigen (PCNA) immunostaining, which was performed using a monoclonal Mouse Anti-PCNA Clone PC 10, Dako, Denmark, diluted 1:100, and used with Dako EnVision TM,
EnVision TM double staining and LASABTM 2 systems. The staining procedure follows the instructions included within the detection system used. Positive and negative controls were run simultaneously with biopsy specimen. Oral squamous cell carcinoma biopsies cases served as positive controls. Five sections were randomly chosen for each animal. Approximately 1000 cells from cell population were counted at a magnification of 400X, and the percentages of PCNA positive cells were calculated. All microscopic analyses were performed using a light microscope (Olympus, Tokyo, Japan). To ensure the objectivity of the analysis, the evaluation was carried out by two independent observers. Eyepiece mounted with counting grids was used for counting. The intensity of staining was not considered for evaluation. The level of PCNA expression was evaluated according to the scoring system of Seleit et al. $(2010)^{18}$ The application of this system gives a score ranging from 0 to 3 for degree of positivity: Percentage of positively stained cells (negative: $<1 \%$, mild: 1 $10 \%$, moderate: $>10-50 \%$, strong: $>50 \%$ ).

Statistical analysis: After necessary data had been collected, the results were given as mean \pm standard deviation. Statistical significance of differences between two groups was tested with the Mann-Whitney$U$ test. A $P$ value less than or equal to 0.05 was considered statistically significant.

\section{Results}

\section{A. Hematoxylin and eosin results:}

Microscopic examination of the rat's tongue mucosa of the Saline/Water and Saline/ Ascorbic acid treated groups at day four and eight showed that the ventral surface of the tongue was normal and the oral mucosa covering the underside of the tongue being composed of keratinized stratified squamous epithelium. The lamina propria was generally thin, contained collagen fibers and small blood vessels. Groups of well formed striated muscles $\mathrm{x}$ 
https://doi.org/10.15218/zjms.2017.002

were also noticed beneath the lamina propria, and no inflammatory cells infiltration or congested blood vessels were seen (Figure 1). At day four, photomicrograph of the ventral tongue mucosa of rats in the CTX/ Water treated group showed a marked pathological changes like decrease in the thickness of the epithelium and keratin layer, cellular changes, separation of keratin, cytoplasmic vacuolation of some epithelial cells which appear with hyper chromatic nuclei, flattening of rete ridges, inflammatory infiltrate, and severe edema and vascular congestion in the connective tissue. At day eight, the CTX / Water treated groups showed an increase in the thickness of the epithelium, all cellular

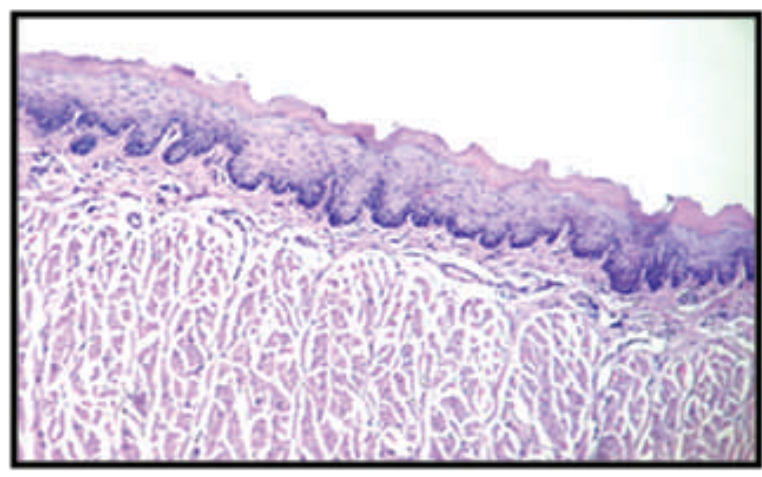

A1

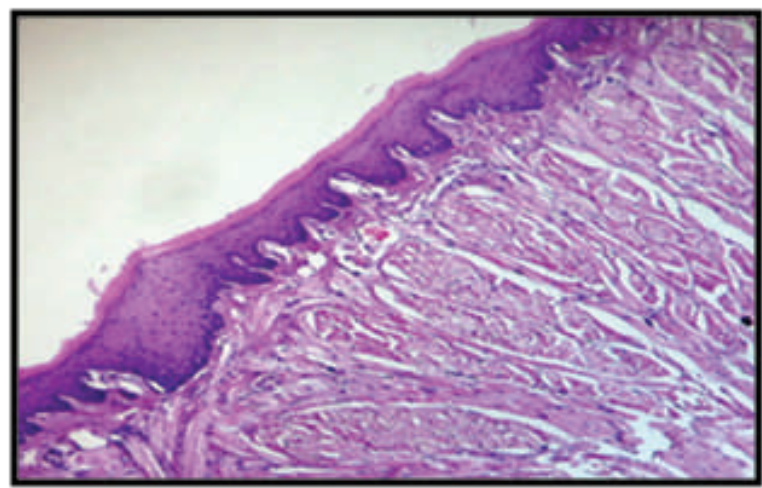

B1

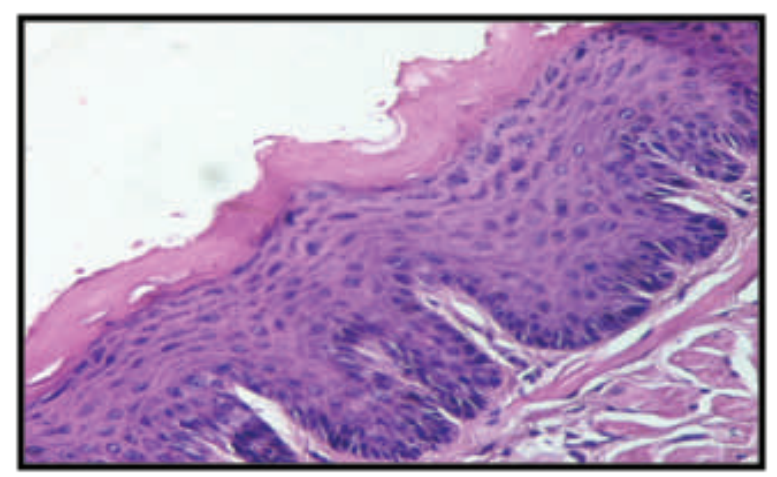

A2

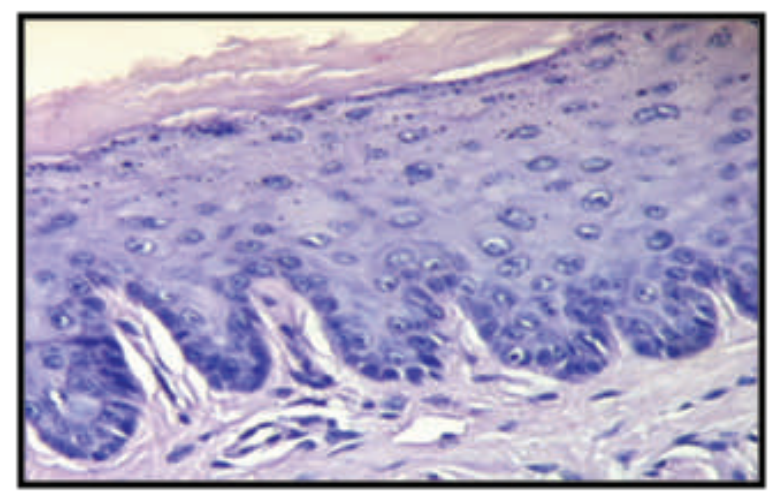

B2

Figure 1: Photomicrograph of the ventral tongue mucosa of rat in the Saline / Water treated group at day four (A1: H\&Ex100) and eight (A2: H\&Ex400) reveal normal keratinized squamous epithelium and normal connective tissue, which shows absence of subepithelial inflammatory cells and congested blood vessels. Photomicrograph of the ventral tongue mucosa of rat in the Saline / Ascorbic acid treated group at day four (B1: H\&Ex100) and eight (B2: H\&Ex400) reveal normal keratinized squamous epithelium and normal connective tissue. 
changes, and epithelial vacuolation was still present, but are less than that at day four (Figure 2). At day four, photomicrograph of the ventral tongue mucosa of rats in the CTX/Ascorbic acid treated group showed increase in the thickness of the epithelium and keratin layer, less cellular changes, less

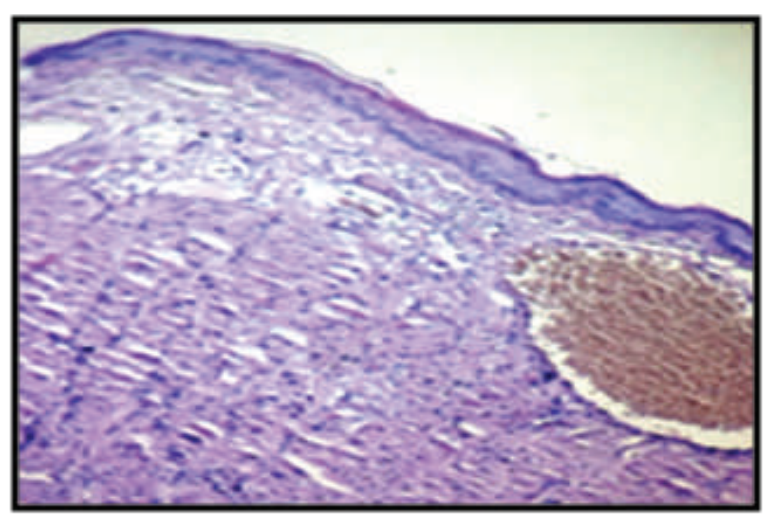

A1

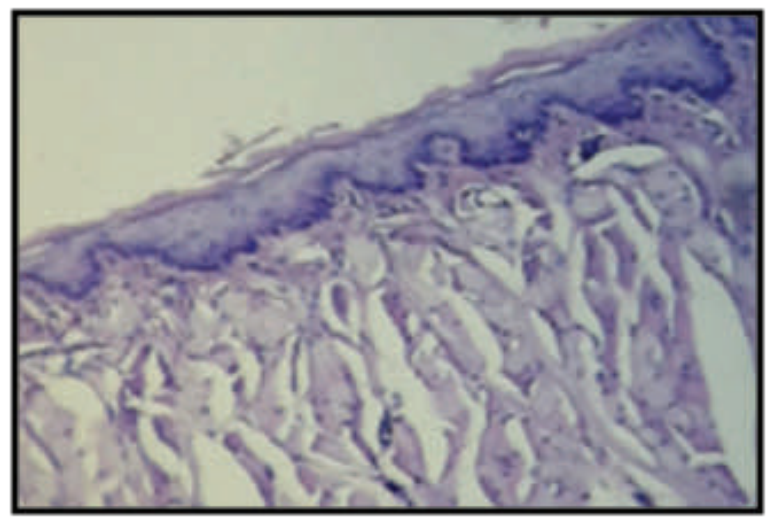

B1 inflammatory infiltrate and vascular hyperemia in the connective tissue, with restoration of rete ridges in comparison with the CTX/ Water treated group at this day. At day eight, there was an increase in the thickness of epithelium and keratin layer with elongation of rete ridges (Figure 3).

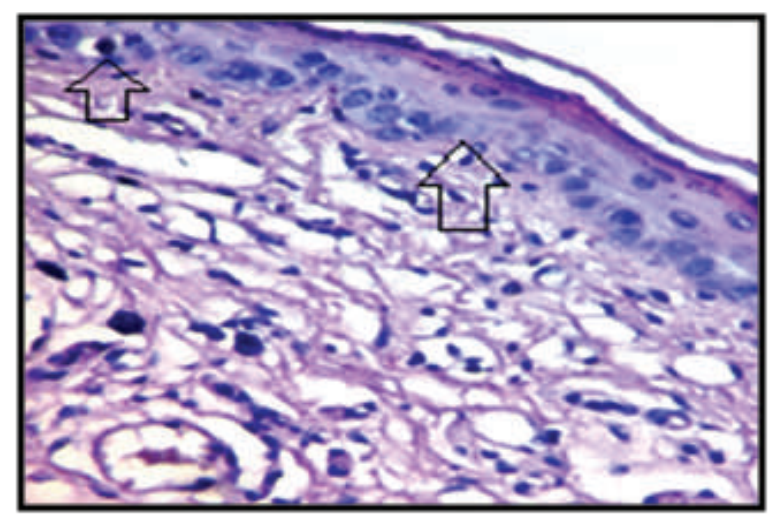

A2

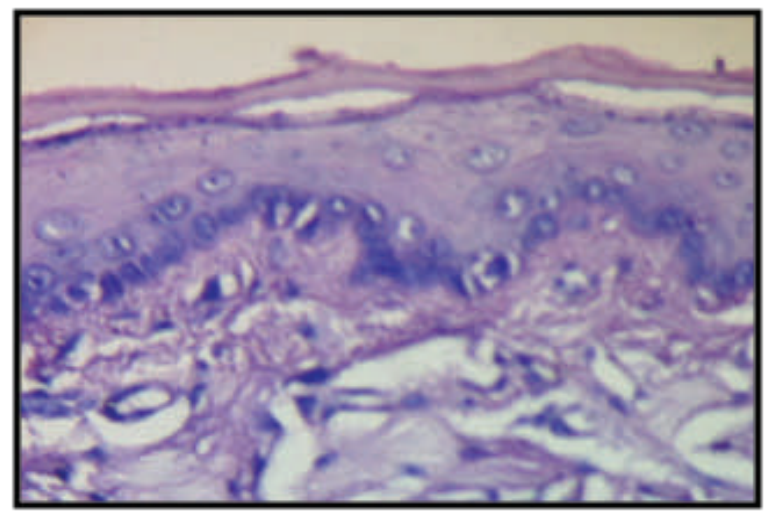

B2

Figure 2: Photomicrograph of the ventral tongue mucosa of rat in the CTX/ Water treated group at day four (A1: H\&Ex100; A2: H\&Ex400) shows severe decrease in the thickness of the epithelium and keratin layer, separation of keratin, cytoplasmic vacuolation of some epithelial cells (left arrow), loss of basal layer in some area (right arrow), flattening of rete ridges, edema, and vascular congestion. At day eight (B1: H\&Ex100) slight increase in the thickness of the epithelium is seen, but cellular changes like epithelial vacuolation are still present (B2: H\&Ex400). 
B. Morphometric results:

Epithelial thickness: In the control groups, at day four, the mean epithelial thicknesses in the Saline/Water and Saline/ Ascorbic acid treated groups were $49.99 \pm 0.54$ and $51.2 \pm 0.28$ respectively. At day eight, the mean epithelial thicknesses in the Saline/Water and Saline/Ascorbic acid treated groups were $50.33 \pm 0.42$ and

A1

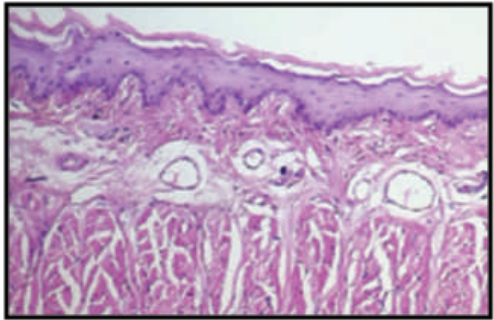

B1

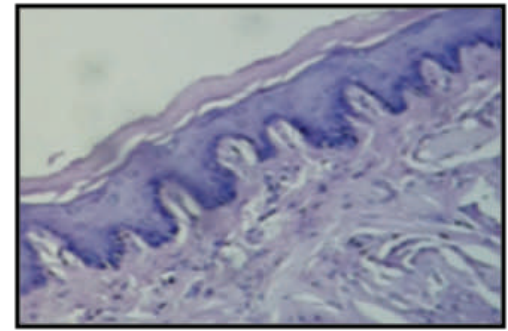

$51.5 \pm 0.18$ respectively. Statistical analysis showed that there were no significant differences $(P>0.05)$ present between these groups regarding the epithelial thickness at day four $(P=0.240)$ and eight $(P=0.251)$, so Saline/Water treated group was considered the reference one for the control groups (Table 1).

A2

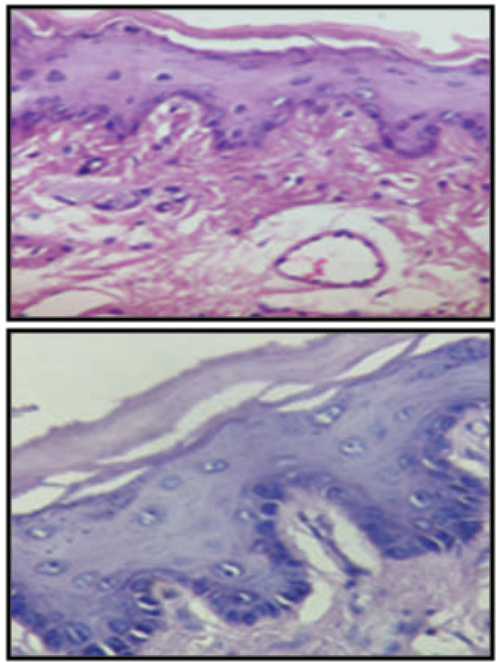

Figure 3: Photomicrograph of the ventral tongue mucosa of rat in the CTX / Ascorbic acid treated group, at day four (A1: H\&Ex100) shows increase in the thickness of the epithelium in comparison with CTX/Water treated group at this day, with restoration of the shape of rete ridges, cytoplasmic vacuolation of some epithelial with vascular hyperemia in the connective tissue are also seen (A2: H\&Ex400). At day eight (B1: H\&Ex100; B2, H\&Ex400) the photomicrograph shows an increase in the thickness of epithelium which is more than CTX/Water treated groups at this day.

Table 1: Means and standard deviations of epithelial thickness and damage scores of the ventral surface of tongue following water or ascorbic acid treatment in Albino rats post saline or CTX injection of all groups in the study.

\begin{tabular}{|c|c|c|c|c|c|}
\hline Groups & & 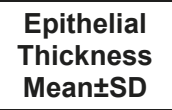 & $P$-value & $\begin{array}{c}\text { Damage } \\
\text { Score } \\
\text { Mean } \pm S D\end{array}$ & $P$ value \\
\hline $\begin{array}{l}\text { Saline/Water } \\
\text { Saline/Ascorbic acid }\end{array}$ & Day 4 & $\begin{array}{c}49.99 \pm 0.54 \\
51.2 \pm 0.28\end{array}$ & 00.240 & $\begin{array}{l}0.13 \pm 0.26 \\
0.23 \pm 0.31\end{array}$ & 0.188 \\
\hline $\begin{array}{l}\text { Saline/Water } \\
\text { Saline/Ascorbic acid }\end{array}$ & Day 8 & $\begin{array}{c}50.33 \pm 0.42 \\
51.5 \pm 0.18\end{array}$ & 0.251 & $\begin{array}{l}0.14 \pm 0.51 \\
0.29 \pm 0.14\end{array}$ & 0.217 \\
\hline $\begin{array}{l}\text { Saline/Water } \\
\text { CTX/Water }\end{array}$ & Day 4 & $\begin{array}{c}49.99 \pm 0.54 \\
10.075 \pm 0.52\end{array}$ & 0.0120 & $\begin{array}{l}0.13 \pm 0.26 \\
3.65 \pm 0.32\end{array}$ & 0.0120 \\
\hline $\begin{array}{l}\text { Saline/Water } \\
\text { CTX/Water }\end{array}$ & Day 8 & $\begin{array}{l}50.33 \pm 0.42 \\
17.23 \pm 0.34\end{array}$ & 0.0120 & $\begin{array}{l}0.14 \pm 0.51 \\
2.23 \pm 0.15\end{array}$ & 0.0120 \\
\hline $\begin{array}{l}\text { Saline/Water } \\
\text { CTX/Ascorbic acid }\end{array}$ & Day 4 & $\begin{array}{l}49.99 \pm 0.54 \\
23.98 \pm 0.83\end{array}$ & 0.0120 & $\begin{array}{l}0.13 \pm 0.26 \\
2.45 \pm 0.58\end{array}$ & 0.0120 \\
\hline $\begin{array}{l}\text { Saline/Water } \\
\text { CTX/Ascorbic acid }\end{array}$ & Day 8 & $\begin{array}{l}50.33 \pm 0.42 \\
36.34 \pm 0.47\end{array}$ & 0.0120 & $\begin{array}{l}0.14 \pm 0.51 \\
1.51 \pm 0.38\end{array}$ & 0.0120 \\
\hline $\begin{array}{l}\text { CTX/Water } \\
\text { CTX/Ascorbic acid }\end{array}$ & Day 4 & $\begin{array}{c}10.075 \pm 0.52 \\
23.98 \pm 0.83\end{array}$ & 0.0120 & $\begin{array}{l}3.65 \pm 0.32 \\
2.45 \pm 0.58\end{array}$ & 0.0120 \\
\hline $\begin{array}{l}\text { CTX/Water } \\
\text { CTX/Ascorbic acid }\end{array}$ & Day 8 & $\begin{array}{l}17.23 \pm 0.34 \\
36.34 \pm 0.47\end{array}$ & 0.0120 & $\begin{array}{l}2.23 \pm 0.15 \\
1.51 \pm 0.38\end{array}$ & 0.0120 \\
\hline
\end{tabular}


At day four, the mean epithelial thicknesses in the CTX/Water and CTX/Ascorbic acid treated groups were $10.075 \pm 0.52$ and $23.98 \pm 0.83$ respectively. At day eight, the mean epithelial thicknesses in the CTX/ Water and CTXI Ascorbic acid treated groups were $17.23 \pm 0.34$ and $36.34 \pm$ 0.47 , respectively. At day four and eight, statistical analysis showed that there were significant differences $(P<0.05)$ present between Saline/Water and CTX/Water treated groups $(P=0.0120)$, Saline/Water and CTXI Ascorbic acid treated group $(P=0.0120)$. The results also showed that there were significant differences $(P<0.05)$ present between CTX/Water and CTX/ Ascorbic acid treated group at day four and eight $(P=0.0120)$.

Damage score: In the control groups, at day four, the mean damage score in the Saline/Water, and Saline/ Ascorbic acid treated groups were $0.13 \pm 0.26$, and 0.23 \pm 0.31 respectively. At day eight, the mean damage score in the Saline/Water and Saline/Ascorbic acid treated groups were $0.14 \pm 0.51$ and $0.29 \pm 0.14$ respectively (Table 1). Statistical analysis of these two control groups showed that there was no significant differences present between these groups regarding the damage score at day four $(P=0.188)$ and eight $(P=0.217)$, so Saline/Water treated group was considered the reference one for the control groups. At day four, the mean damage scores in the CTX/Water and CTX/ Ascorbic acid treated groups were (3.65 \pm $0.32)$ and $(2.45 \pm 0.58)$ respectively. At day eight, the mean damage scores in the CTX/ Water and CTXI Ascorbic acid treated groups were $(2.23 \pm 0.15)$ and (1.51 \pm 0.38) respectively. At day four and eight, statistical analysis showed that there were significant differences $(P<0.05)$ present between Saline/Water and CTX/Water treated groups, Saline/Water and CTXI Ascorbic acid treated group $(P=0.0120)$. The results also showed that there was significant differences present between CTX/Water and CTX/ Ascorbic acid treated group at day four and eight $(P=0.0120)$.

\section{Immunohistochemical result:}

The effect of ascorbic acid treatment on cell proliferation was evaluated using PCNA. A moderate immune expression was observed in the tongue epithelial cells of control groups at day four and eight respectively. However, CTX/Water and CTX/ Ascorbic acid treated groups revealed mild immune reaction on day four, but it was moderate at day eight (Figure 4). In the control groups, at day four, the mean immune expression in the Saline/Water, and Saline/ Ascorbic acid treated groups were $18.12 \pm 1.26$, and $17.84 \pm 0.31$ respectively. At day eight, the mean immune expression in the Saline/Water and Saline/ Ascorbic acid treated groups were $19.02 \pm 0.51$ and $18.82 \pm 0.14$ respectively. Statistical analysis of these two control groups showed that there was no significant differences present between these groups regarding the immune expression at day four $(P=0.268)$ and eight $(P=0.227)$ respectively, so Saline/ Water treated group was considered the reference one for the control groups. At day four, the mean immune expression in the CTX/Water and CTX/Ascorbic acid treated groups were $6.05 \pm 0.62$ and $9.94 \pm 0.21$, respectively. At day eight, the mean immune expression in the CTX/ Water and CTXI Ascorbic acid treated groups were $10.39 \pm 0.55$ and $14.72 \pm$ 0.32 , respectively. At day four and eight, statistical analysis showed that there were significant differences $(P<0.05)$ present between Saline/Water and CTX/Water treated groups, Saline/Water and CTX/ Ascorbic acid treated group $(P=0.0120)$. The results also showed that there was significant differences present between CTX/Water and CTX/ Ascorbic acid treated group at day four and eight $(P=0.0120)$. 


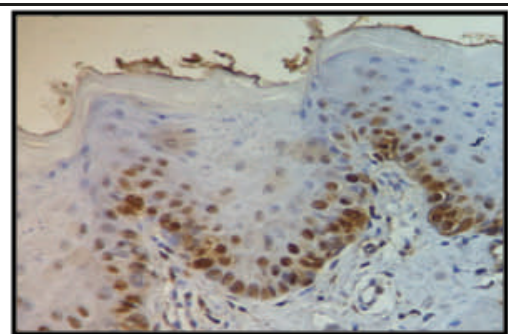

A1

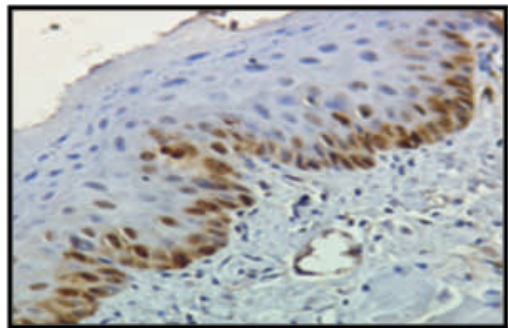

B1

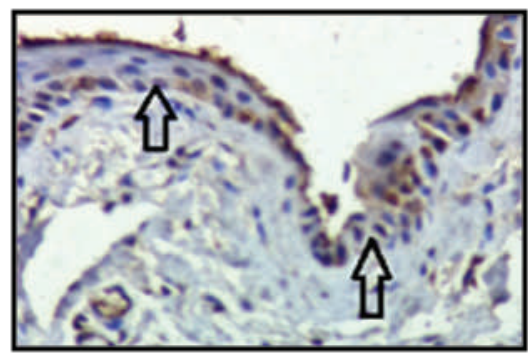

C1

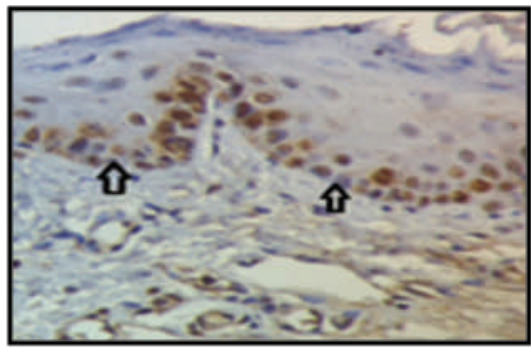

D1

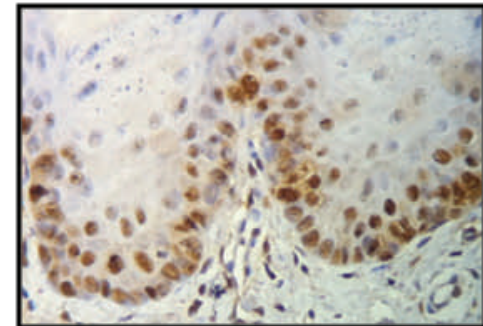

A2

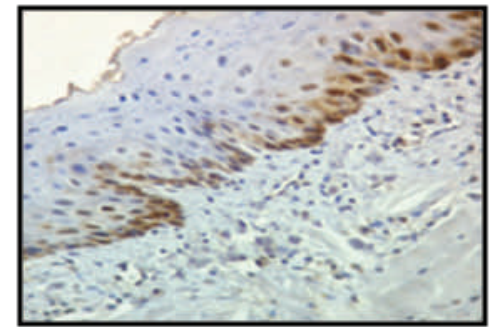

B2

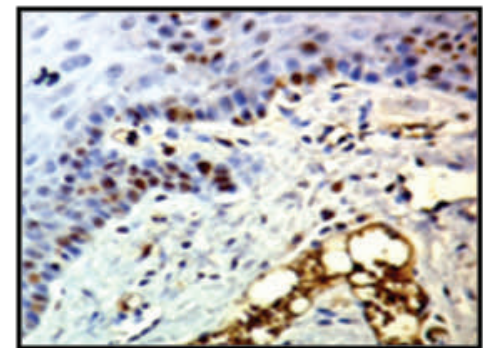

C2

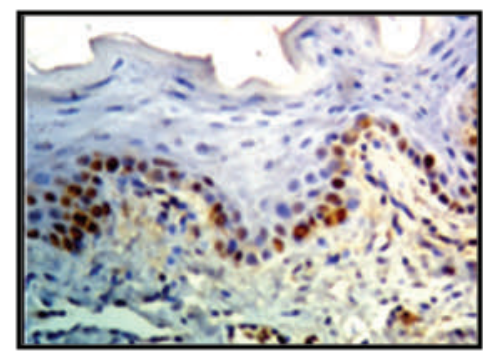

D2

Figure 4: Immunohistochemical result for PCNA: A1 and A2: Saline/Water treated group at day four and eight respectively showing moderate immune expression of PCNA (Immunohistochemistry x400). B1 and B2: Saline/Ascorbic acid treated group at day four and eight respectively showing moderate immune expression of PCNA (Immunohistochemistry $\mathrm{x} 400$ ). C1, CTX/Water treated group at day four showing mild immune expression of PCNA; the positive cells are missing in some basal layer cells (arrows). C2, CTX/Water treated group at day eight showing moderate immune expression of PCNA (Immunohistochemistry x400). D1, CTX/ Ascorbic acid treated group at day four showing mild immune expression of PCNA; the positive cells are missing in some basal layer cells (arrows). D2: CTX/Ascorbic acid treated group at day eight showing moderate immune expression of PCNA (Immunohistochemistry x400). 


\section{Discussion}

Oral mucositis is currently considered to be the most severe non-hematological complication of anticancer therapy which leads to a considerably decreased quality of life in these patients, due to dysphagia, dysarthria and odynophagia; in addition, the lesions may represent a gateway for opportunistic infections. ${ }^{19}$ In the control groups of present study, statistical analysis at day four and eight showed that there was nonsignificant differences $(P>0.05)$ present between the Saline/Water treated group and the Saline/ Ascorbic acid group regarding the epithelial thickness, damage scores, and rate of proliferation. Complementary and alternative medical practitioners worldwide currently use ascorbate intravenously in patients, in part because there are no apparent harmful effects. ${ }^{20-21}$ Several studies found that ascorbic acid affects the tumor cells but not the normal cells. In vitro studies showed that ascorbic acid is cytotoxic to many malignant cell lines. ${ }^{22}$ The key element in tumor cells is p53, a transcription factor that modulates stresses to DNA. It can thwart the growth of tumors, halt a tumor cell in the middle of its metabolic cycle, and cause tumor cells to die. ${ }^{23}$ P53 has been shown to increase cellular oxidative stress, which helps to destroy cancer cells or at least to inhibit their growth. Ascorbate cytotoxicity seems to be more effective in cells with higher levels of p53, and because the natural body cells have lower levels of p53 than tumor cells, ascorbate does not damage these cells as much. ${ }^{23}$ The CTXI Water treated group of the present study showed a significant decrease in epithelial thickness, a significant increase in damage scores, and a significant decrease in PCNA immune expression. Zhao et al. $(2009)^{24}$ found the same changes in the tongue of mice, but following radiation. Inflammatory stage occurs due to a direct effect of the chemotherapeutic drug, which stimulates the early release of chemical mediators by neutrophils and interleukin-1 by macrophages and lymphocytes. These pro-inflammatory cytokines trigger a prompt inflammatory response resulting in increased vascular permeability in the subepithelial connective tissue. ${ }^{25}$ The action of the drug is associated with the release of free radicals and inhibits the mitosis of the basal cell layer of the mucosal epithelium by directly damaging cellular DNA. An acute inflammatory reaction occurs and promotes predominant diapedesis of neutrophils that release vasoactive and chemotactic mediators. Cytokines released from keratinocytes, endothelial cells and the cells of the lamina propria enhance cell damage; concomitantly, chemotherapeutic drugs activate enzymes that increase apoptosis. ${ }^{26}$ The chemotherapy generates ROS which is deleterious to the DNA of epithelial cells. ROS may induce a cascade of biological events, which in turn result in the synthesis of various pro-inflammatory cytokines. These cytokines target epithelium, endothelium and connective tissue, thereby causing tissue injury and inflammatory response resulting in increased subepithelial vascularity. ${ }^{27,28}$ A significant decrease in PCNA immune expression in comparison with the CTX/ Ascorbic acid treated group was also seen $(P<0.05)$. Aboushady et al. $(2012)^{29}$ found a noticeable reduction in PCNA expression in irradiated rats. PCNA is localized in the nucleus and is associated with cell proliferation. All these histopathological changes seen decreased at day eight. Some authors ${ }^{30}$ found that the toxicity of CTX regarding the increased apoptosis and decreased proliferation decreased gradually after 24 hours from the intraperitoneal injection. A significant increase in epithelial thickness, significant decrease in damage score, and significant increase in PCNA immune expression seen in the CTX/Ascorbic acid treated group in comparison with the CTX/Water treated group at day four and eight. When the cells are oxidized, they often release free radicals such as ROS, they can be converted into more destructive oxidative 
species, and these when they bind to a natural body cell, can cause the cell's DNA to mutate. As an antioxidant, ascorbic acid can neutralize these free radicals and keep them from damaging natural cells. ${ }^{31}$ It was found that ascorbic acid can repair the connective tissue, and accelerate the healing of wounds, can promote resistance to infections, and has an anti-inflammatory effect. $^{32}$ In addition, it can impede the release of $\mathrm{C}$-reactive proteins, interleukin6 , TNF- $\alpha$, and ROS from several types of cells involved in inflammation, ${ }^{33}$ and promote endothelial cell proliferation, and decrease growth inhibition and apoptosis induced by TNF- $\alpha$ oxidative stress. ${ }^{34}$ The most abundant free radicals that cause cell damage are oxidized versions of glutathione, a non-enzymatic peptide that typically acts as an antioxidant. Because ascorbic acid can keep glutathione from becoming oxidized, it can keep the levels of non-oxidized glutathione high in the body, thereby reducing the damage caused by this free radical in its oxidative state. ${ }^{35}$ Suhail et al. (2012) ${ }^{35}$ measured the activity of several different enzymes that scavenge or neutralize free radicals. Comparison between treating twenty breast cancer patients with both chemotherapy and ascorbic acid and another twenty with chemotherapy alone, they found that individuals who also supplemented with ascorbic acid treatment had higher levels of free radical enzymes like glutathione-Stransferase, and glutathione reductase, and had lower levels of DNA damage than those who were administered chemotherapy alone. Ascorbic acid can also protect against the harmful effects of 8 -oxoguanine, which has been found to be mutagenic to natural cells' DNA. Some authors $^{36}$ found that the cancer patients who took $500 \mathrm{mg}$ of ascorbic acid daily experienced a decrease of 8-oxoguanine concentrations compared to those who were not taking ascorbic acid supplements. In another study, the results were similar: there was a negative correlation between ascorbic acid dosage, and the level of 8-oxodeoxyguanosine, which can also be harmful to DNA. ${ }^{37}$ Lipid peroxidation mediated by free radicals is considered to be the major mechanism of cell membrane destruction and cell damage ${ }^{38}$. Based on these findings, it was determined that consistently high doses of ascorbic acid could allow the inhibition of lipid peroxidation in cancer patients. ${ }^{37}$

\section{Conclusion}

CTX has a deleterious effect on the oral mucosa leading to marked morphometric and microscopic changes. Ascorbic acid can protect the oral mucosa from CTX-induced cytotoxicity, and attenuate or decrease the associated injury.

\section{Conflicts of interest}

The author reports no conflicts of interest.

\section{References}

1. Ghom AG, Jedhe SM. Text book of oral pathology. $2^{\text {nd }}$ edition. New Delhi: Jaypee Brothers, Medical Publishers Pvt. Limited; 2013.

2. Da Cruz Campos MI, Campos CN, Aarestrup FM, Aarestrup JV. Oral Mucositis in cancer treatment: Natural history, prevention and treatment (review). Mol Clin Oncol 2014; 2(3):337-40.

3. Miller MM, Donald DV, Hagemann TM. Prevention and treatment of oral mucositis in children with cancer. J Pediatr Pharmacol Ther 2012; 17(4): 340-50.

4. Sonis ST. A biological approach to mucositis. J Support Oncol 2004; 2(1):21-32.

5. Aras MH, Sezer U, Erkilic S, Demir T, Dagli SN. Effect of dietary boron on 5- fluorouracil induced oral mucositis in rats. Eur J Dent 2013; 7(3):10-4.

6. Javed A, Ashwini LS, TS, Sagar S, Medam SK. Effect of quercetin on cyclophosphamide induced biochemical profiles in rat liver. Int J Res Stud Biosci 2014; 2:40-6.

7. Khan S, Jena G. Sodium cylophosphamideinduced genotoxicit and cytotoxicity in the colon of mice. J Basic Clin Physiol Pharmacol 2014; 27:1-11.

8. Panigrahy SK, Jatawa S, Archana Tiwari A. Therapeutic use of cyclophosphamide and its cytotoxic action : A challenge for researchers. J Pharm Res. 2011; 4(8):2755-7.

9. Doloff JC, Chen C,David J Waxman DJ. Anti-tumor innate immunity activated by intermittent metronomic cyclophosphamide treatment of brain tumor xenografts is preserved by anti-angiogenic drugs that spare VEGF receptor-2. Mol Cancer 2014; 13:158-71. 
10. Fassbinder T, Saunders U, Mickholz E, Jung E, Becker H, Schlüter B, et al. Differential effects of cyclophosphamide and mycophenolate mofetil on cellular and serological parameters in patients with systemic lupus erythematosus. Arthritis Res Ther 2015; 17:92-114.

11. Fukazawa M, Kawaguchi $H$, Shigematsu $H$, Koga C, Mori E, Nishimura S, et al. High incidence-rate of oral mucositis in breast cancer patients receiving anthracycline-based chemotherapy (FEC100). Jpn J Cancer Chem 2012; 39(3): 395-8.

12. Keefe DM, Schubert MM, Elting LS, Sonis ST, Epstein JB, Raber-Durlacher JE, et al. Mucositis study section of the multinational association of supportive care in cancer and the International Society for Oral Oncology. Updated clinical practice guidelines for the prevention and treatment of mucositis. Cancer 2007; 109(5): 820-31.

13. Al-Refai AS, Al-Barazenchy $\mathrm{H}$, Khalil A K. Immunohistochemical study of the effect of green tea extract on methotrexate- induced oral mucositis in albino rats. J Cytol Histol 2014; 5 (3):1-7.

14. El-Gendy KS, Aly NM, Mahmoud FH, Kenawy A, El-Sebae AK. The role of vitamin $C$ as antioxidant in protection of oxidative stress induced by imidacloprid. Food Chem. Toxicol 2010; 48:215-21.

15. Nadia RA, Abou-Zeid. Ameliorative effect of vitamin $C$ against 5-fuorouracil -induced hepatotoxicity in mice: A light and electron microscope study. J Basic Appli Zool 2014; 67:109 -18 .

16. Owari M, Wasa M, Oue T, Nose S, Fukuzawa M. Glutamine prevents intestinal mucosal injury induced by cyclophosphamide in rats. Pediatr Surg Int 2012; 28(3):299-303.

17. Ücuncu $H$, Ertekin MV, Yoruk Ö, Sezen O, Özkan A, Erdog ${ }^{\circ} \mathrm{AN} F$, et al. Vitamin $E$ and L-carnitine, separately or in combination, in the prevention of radiation-induced oral mucositis and myelosuppression: a controlled study in a rat model. J Radiat Res 2006; 47:91-102.

18. Seleit IA, Asaad N, Maree A, Abdel Wahed M. Immunohistochemical expression of p53 and $\mathrm{Ki}-67$ in cutaneous lupus erythematosus. J Egypt Women Dermatol Soc 2010; 7(1):5-15.

19. Sonis ST. Efficacy of palifermin (keratinocyte growth factor-1) in the amelioration of oral mucositis. Core Evid 2010; 4:199-205.

20. Riordan NH, Riordan HD, Casciari JJ. Clinical and experimental experiences with intravenous vitamin C. J Orthomol Med 2000; 15:201-3.

21. Riordan HD, Hunninghake RB, Riordan $\mathrm{NH}$, Jackson JJ, Meng $\mathrm{X}$, Taylor $\mathrm{P}$, et al. Intravenous ascorbic acid: protocol for its application and use. P R__Health Sci J 2003; 22 (3):287-90
22. Sakagami H, Satoh K, Hakeda Y, Kumegawa M. Apoptosis- inducing activity of vitamin $\mathrm{C}$ and vitamin K. Cell Mol Biol 2000; 46:129-35.

23. Kim J, Lee SD, Chang $B$, Jin DH, Jung $S$, Park MY, et al. Enhanced antitumor activity of vitamin C via p53 in cancer cells. Free Radic Biol Med 2012; 53(8):1607-15.

24. Zhao J, Kim KA, De Vera J. Spondin 1 protects mice from chemotherapy or radiation-induced oral mucositis through the canonical Wnt/beta-catenin pathway. Proc Natl Acad Sci 2009; 106:2331-6.

25. Lalla RV, Sonis ST, Peterson DE. Management of oral mucositis in patients who have cancer. Dent Clin North Am 2008; 52:61-77.

26. Lima V, Vidal FD, Rocha FA, Brito GA, Ribeiro RA. Effects of tumor necrosis factor-alpha inhibitors pentoxifylline and thalidomide on alveolar bone loss in short-term experimental periodontal disease in rats. J Periodontol 2004; 75:162-8.

27. Shih A, Miaskowski C, Dodd M, Stotts N, MacPhail L. Mechanisms for radiation-induced oral mucositis and the consequences. Cancer Nurs 2003; 26(3):222-9.

28. Cawley MM, Benson LM. Current trends in managing oral mucositis. Clin J Oncol Nurs 2005; 9(5):584-92.

29. Aboushady IM, Mubarak RT,; El-mougy SAF, Rashed LA, El-desouky AA. The effect of transplanted bone marrow Sstem cells on the tongue of irradiated rats (Histological and Immunohistochemical study). J Am Sci 2012; 8 (11):553-61.

30. Jezernik K1, Romih R, Mannherz HG, Koprivec D. Immunohistochemical detection of apoptosis, proliferation and inducible nitric oxide synthase in rat urothelium damaged by cyclophosphamide treatment. Cell Biol Int 2003; 27(10):863-9.

31. Ratnam DV, Ankola DD, Bhardwaj V, Sahana DK, Ravi Kumar MNV. Role of antioxidants in prophylaxis and therapy: a pharmaceutical perspective. J Control Release 2006; 113(3): 189-207.

32. Naidu KA. Vitamin $C$ in human health and disease is still a mystery? An overview. Nutr J 2003; 2:7-11.

33. Mikirova N, Casciari J, Rogers A, Taylor P. Effect of high-dose intravenous vitamin $C$ on inflammation in cancer patients. J Transl Med 2012; 10(1):189-98.

34. Saeed RW, Peng T, Metz CN. Ascorbic acid blocks the growth inhibitory effect of tumor necrosis factor-alpha on endothelial cells. Exp Biol Med 2003; 228:855-65.

35. Suhail N, Bilal N, Khan HY, Hasan S, Sharma S, Khan $F$, et al. Effect of vitamins $C$ and $E$ on antioxidant status of breast-cancer patients undergoing chemotherapy. J Clin Pharm Ther 2012; 37:22-6. 
36. Podmore ID, Griffiths HR, Herbert KE, Mistry N, Mistry P, Lunec J. Vitamin C exhibits pro-oxidant properties. Nature 1998; 392(6676):559-64.

37. Lee KW, Lee HJ, Surh YJ, Lee CY. Vitamin C and cancer chemoprevention: reappraisal. Am J Clin Nutr 2003; 78(6):1074-8.

38. Mohan S, Priya V. Changes in lipid peroxidation, glutathione,ascorbic cid, vitamin $\mathrm{E}$ and antioxidant enzymes in patients with ovarian cancer. Acta Med Acad 2009: 38(1):1-5. 